\title{
Interventions to improve recruitment an retention of physicians in rural and remote Canada: A systematic review
}

Claire Lafortune, Jeffrey Gustafson

\section{ABSTRACT}

Introduction: Rural and remote regions of Canada struggle to attract and retain an adequate healthcare workforce to provide the healthcare needed by their local residents. The purpose of this systematic review is to explore current literature that has analyzed strategies for recruitment and retention of physicians to rural and remote regions in Canada.

Methods: Scopus and PubMed were searched for articles. To be included in the review, the titles yielded from the initial search had to be in English and meet one of the inclusion criteria: (1) address rural and/or remote healthcare, (2) focus on medical students or physicians, and (3) discuss recruitment or retention strategies. Titles were excluded if they discussed nonOECD countries or were not original journal articles. The final sample of articles were analyzed by both reviewers for content and emerging themes.

Summary of Results and Conclusion: The initial search yielded a total of 3397 titles for review. After applying criteria described above, 35 articles remained for review. A variety of recruitment and retention themes were identified targeting physicians before, during, and after their medical education. The most effective strategies consistently appear to be those aimed before medical education, specifically admitting medical students who have a rural background. This review aims to provide a summary of the currently available research to assist with evidence-based decision making to increase supply and retention of rural physicians.

Keywords: rural medicine; physician recruitment; physician retention; primary care

\section{INTRODUCTION}

Rural and remote regions of Canada struggle to attract and maintain an adequate healthcare workforce to provide for local residents. The 2016 Canadian census reported that $16.8 \%$ of the population lived in rural areas, ${ }^{1}$ while only $8.2 \%$ of the country's physicians practiced outside urban centres. ${ }^{2}$ Numerous interventions have been attempted in order to resolve this issue with varying degrees of success. ${ }^{3,4}$ In order to guide these interventions, many studies have been performed to determine which factors lead physicians to practice rural medicine. ${ }^{3,5,6}$

This systematic review explores the current literature assessing barriers to the recruitment and retention of rural physicians as well as strategies used to attract medical students and physicians to rural and remote regions within Canada. The purpose of this review is to provide Canadian governments, hospitals, and medical schools with a summary of current research to assist with implementation of evidence-based strategies aimed to increase the supply and retention of rural physicians.

\section{METHODS}

The search was performed using two databases: Scopus and PubMed. The authors (CL, JG) collaborated to build the search strategies for each database (Appendix 1 \& Appendix 2).

Two reviewers screened the citations using the following inclusion criteria: the article was available in English, the title belonged to an original research article, and the article was studying an OECD nation. Additionally, the title had to display relevance to one of the following three search categories: (1) a focus on rural, regional, or remote geography, (2) the main group being studied consisted of medical trainees or physicians, or (3) the title demonstrated a focus on the recruitment or retention of medical personnel. The initial 50 titles were assessed for interrater reliability, while the remaining articles were screened by each reviewer independently.

A similar process was applied to the articles undergoing abstract review. The two authors independently applied inclusion and exclusion criteria to the first 50 abstracts. These criteria were the same as those applied to the titles with the added change that abstracts must contain all three of the search categories instead of just one. The remaining abstracts were divided between the two reviewers.

In an effort to narrow the scope of this review and to ensure its relevance to current Canadian populations, full articles were reviewed for the following: 1) published in the year 2000 or later, and 2) focus on Canadian populations. After applying the same procedures used previously for the initial 50 full-text articles, the remaining articles were screened by the reviewers independently.

\section{RESULTS}

The initial search yielded a total of 3397 articles (Figure 1). After applying these criteria to the first 50 titles, the reviewers had $92 \%$ agreement $(k=0.839) .1790$ papers were excluded, leaving 1607 that proceeded to abstract review.

Screening of the first 50 abstracts yielded $94 \%$ agreement $(\mathrm{k}=0.840)$, resulting in a remaining 212 articles that underwent full article review. After full-text review of the first 50 titles, the 


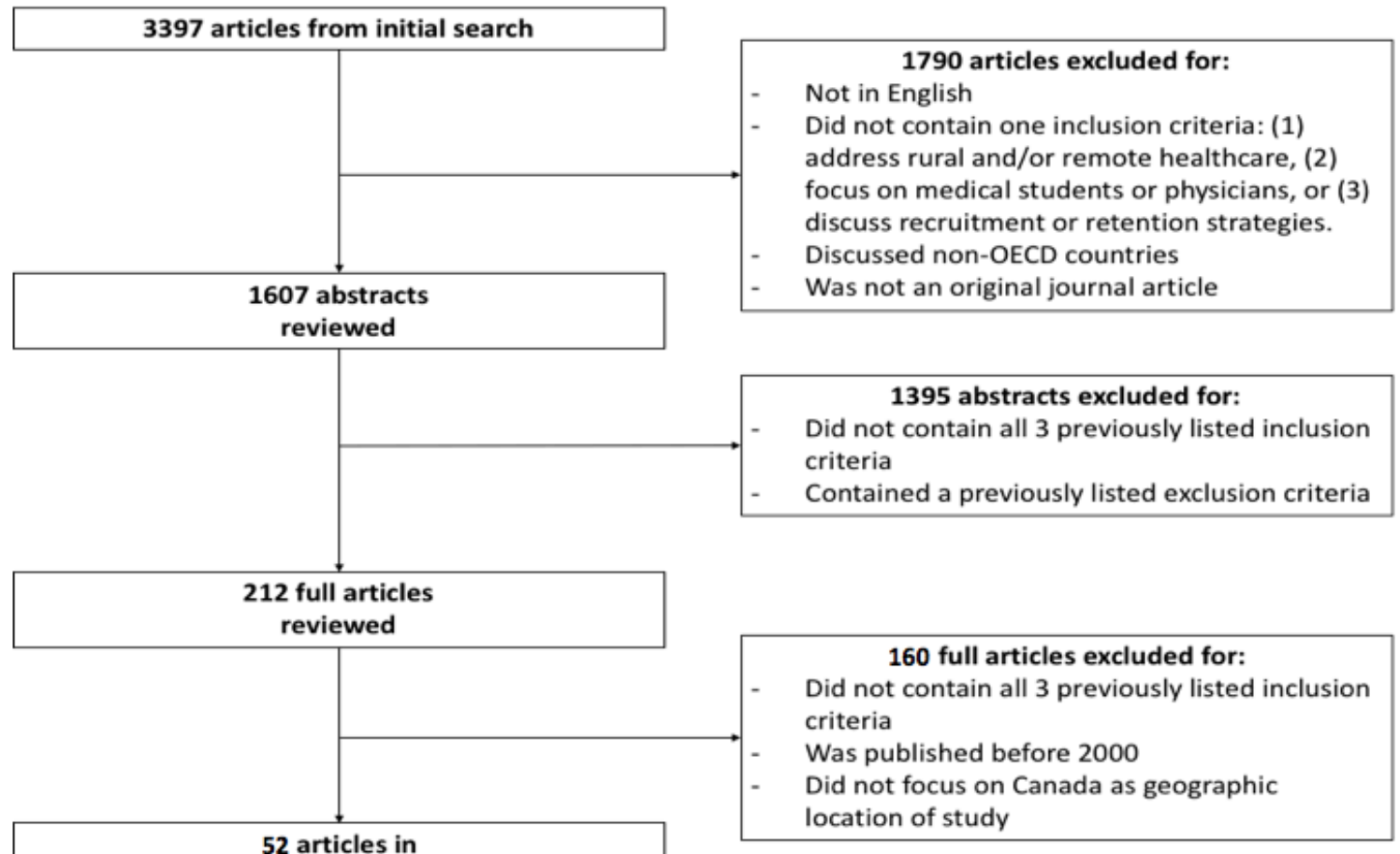

Figure 1: Summary of search results

authors showed 95\% agreement $(\mathrm{k}=0.899) .52$ articles were included and analyzed for content and emerging themes.

Several themes emerged (Table 1): interventions targeted before, during, and after the formal medical education of physicians.

A multitude of factors that contribute to rural and remote regions' struggles to attract and retain physicians were identified. Difficulties in the work environment included feeling professionally isolated without specialist and allied-health resources that are usually available in urban centre, ${ }^{7-10}$ poor access to continuing medical education, ${ }^{7,11}$ and having a large workload with significant time on-call., ${ }^{7,12,13}$ Many physicians find their spouses struggling to find work and enjoy their rural environment, $, 12,14-20$ and others struggled with privacy and confidentiality in the small-town environment. ${ }^{12}$

Before receiving medical education, physicians' intention to practice rurally,21 and having a rural background ${ }^{20-28}$ were found to be significantly associated with future rural practice. During medical education, rural clinical experiences increased the likelihood of future practice., ${ }^{7,220-23,26,27,29-35}$ After physicians completed their medical education, a variety of interventions targeted them. These included access to specialists via telemedicine, ${ }^{8,33}$ access to quality continuing medicine education, ${ }^{17,27,32,33,36,37}$ having quality community resources, ${ }^{11}$ and having appropriate work-life balance (eg limiting call to a maximum of one call shift every five days)..$^{15,37}$

Other qualities that made rural practice more appealing to physicians included developing connections to the
Table 1. Emergent themes from full article eview

\begin{tabular}{lll}
\hline Before Medical & $\begin{array}{l}\text { During Medical } \\
\text { Education }\end{array}$ & $\begin{array}{l}\text { After Completion of } \\
\text { Education }\end{array}$ \\
\hline +Select students for & +Rural training and & +Access to telemedicine \\
medical school from a & learning experiences & supports \\
rural background & during residency & +Provisional licensure to \\
+Select students for & +Positive rural & foreign trained physicians \\
medical school with & experience during & +Working in a community \\
intent to practice & medical education & with good cultural and \\
rurally & +Exposure to strong & educational resources \\
+Perform outreach to & rural mentorship & +Having positive \\
students in rural areas & +Access to high & professional relationships \\
& quality continuing & with specialist and \\
& medical education & generalist colleagues \\
& (CME) & +Being able to have good \\
& +Financial incentives & work life balance \\
& to practicing rurally & +Access to high quality \\
& & continuing medical \\
& & education (CME) \\
& & +Financial incentives to \\
& & practicing rurally \\
& & -Personal life factors \\
& & -Rural work environment \\
& (e.g. isolation, high \\
& workload) \\
\hline
\end{tabular}

Note: "+" denotes an intervention positively affecting recruitment and retention, while "-" denotes a negative impact

community $^{13,33,38}$ and community appreciation. ${ }^{7,15,38}$ Another way to address the lack of rural physicians was recruiting international medical graduates and foreign-trained physicians. ${ }^{39,40}$ A study of provisional licensure of foreign-trained physicians showed that they tended to remain in rural practice at a rate comparable with Canadian-trained physicians. ${ }^{39}$ Finally, financial incentives have 
been shown to improve recruitment and retention of rural physicians before, ${ }^{41}$ during, ${ }^{34,35}$ and after medical education. ${ }^{7,12,13,17,18,20,33,37}$

\section{DISCUSSION}

This review provides a summary of the currently available research on strategies that have been used in Canada to recruit and retain physicians in rural and remote areas. These interventions ranged from targeting students prior to their acceptance into medical school, to strategies focusing on staff physicians who had completed their medical education.

The majority of the strategies reviewed focused on recruiting physicians after they had finished their training through use of financial incentives despite strong evidence that earlier intervention is a more effective approach. ${ }^{42}$ For example, early interventions before and during medical education are the basis of the admissions process and the structure of the undergraduate and postgraduate programs structure of the Northern Ontario School of Medicine (NOSM). NOSM gives admissions preference to students from rural Northern Ontario and requires a nine-month clinical rotation in a rural Northern Ontarian community. As of 2010, 70\% of NOSM graduates chose to train in family medicine, with $67.5 \%$ of NOSM's Family Medicine Residency graduates practicing in Northern Ontario or other rural communities. ${ }^{22}$ This demonstrates the success of early interventions in achieving an increase in the number of locally practicing family physicians. Moreover, a study from Western University has shown that rural exposure during residency training rotations may increase the number of residents who ultimately choose to practice in a rural area. ${ }^{29}$ Additionally, strategies aimed at attracting fully trained physicians after they have completed their training, such as financial incentives, have shown good short-term efficacy but poor long-term. ${ }^{43}$ Unfortunately, the majority of the interventions reviewed in this article fall into this category.

This systematic review has several limitations. Though we narrowed the scope of our search to include only articles pertaining to Canada to ensure relevance to our research question, interventions conducted in other countries may have provided additional insight, though the differing rural demographics would present challenges for interpretation.

This review provides an overview of existing strategies that have been attempted to attract physicians to working in rural and remote environments in Canada. Future areas of research should focus on methods to improve equity throughout the medical school admissions process for students who grew up in a rural or remote environment. Additionally, many of the articles in this review lacked measures of the interventions' efficacy. Future studies should obtain measures of the impact their intervention had on long-term retention rates to provide a strong basis for larger scale interventions. Lastly, there are valuable lessons to learn from approaches other countries have taken in addressing the difficulties of recruiting and retaining physicians in non-urban areas. Additional study of methods used in countries facing similar issues may provide new insight.

\section{APPENDIX 1. SCOPUS SEARCH STRATEGY}

( TITLE-ABS-KEY ( "medical student" OR "medical school" OR "medical education" OR "health student" OR "medical care" OR physician OR "medical trainee" OR "healthcare trainee" OR "health care trainee" OR "clinical school" OR "clinical placement") AND TITLE-ABS-KEY ("rural health care" OR "rural healthcare" OR "rural population" OR "rural area" OR rural OR "medically underserved area" OR "rural medical workforce" OR "remote area" OR "rural exposure" OR "rural track") AND TITLE-ABSKEY ( "health care planning" OR "health care need" OR "medical student recruitment" OR "physician supply" OR "retention" OR "recruitment" OR "physician retention" OR "physician recruitment")) AND (LIMIT-TO (DOCTYPE, "ar") OR LIMITTO (DOCTYPE, “re”)) AND (LIMIT-TO ( SRCTYPE, “j”))

\section{APPENDIX 2. PUBMED SEARCH STRATEGY}

Rural population[mesh terms] OR rural health services[mesh terms] OR rural health[mesh terms] OR hospital, rural[mesh terms] OR rural[all fields] AND Student, medical[mesh terms] OR physicians[mesh terms] OR "medical student"[all fields] OR physician*[all fields] AND Retain[all fields] OR recruit[all fields] OR retent*[all fields] OR intent*[all fields]

\section{REFERENCES}

1. Bollman R. Rural Demography Update 2016 [Internet]. 2016 [cited 2018 Nov 28]. Available from: http://www.ruralontarioinstitute.ca/file. aspx?id=26acac18-6d6e-4fc5-8be6-c16d326305fe

2. Canadian Institute for Health Information. Supply, Distribution and Migration of Physicians in Canada, 2016: Methodological Notes [Internet]. 2017 [cited 2018 Nov 28]. Available from: https://www.cihi. $\mathrm{ca} /$ sites/default/files/document/smdb_data_release_methodology_ notes_phys2016_en.pdf

3. Barer ML 1951-, Stoddart GL 1948-. Improving access to needed medical services in rural and remote Canadian communities : recruitment and retention revisited. 1999 [cited 2018 Nov 29]; Available from: https://open.library.ubc.ca/cIRcle/collections/ facultyresearchandpublications/52383/items/1.0075939

4. Crandall LA, Dwyer JW, Duncan RP. Recruitment and retention of rural physicians: issues for the 1990s. J Rural Health. 1990 Jan;6(1):1938.

5. Rourke JT. Politics of rural health care: recruitment and retention of physicians. CMAJ. 1993 Apr;148(8):1281-4.

6. Easterbrook M, Godwin M, Wilson R, et al. Rural background and clinical rural rotations during medical training: effect on practice location. CMAJ. 1999;160(8):1159-63.

7. Myhre DL, Bajaj S, Jackson W. Determinants of an urban origin student choosing rural practice: a scoping review. Rural Remote Health. 2015;15(3):3483.

8. Duplantie J, Gagnon MP, Fortin JP, et al. Telehealth and the recruitment and retention of physicians in rural and remote regions: a Delphi study. Can J Rural Med. 2007 Winter;12(1):30-6.

9. Miedema B, Hamilton R, Fortin P, et al. The challenges and rewards of rural family practice in New Brunswick, Canada: lessons for retention. Rural Remote Health. 2009 Apr-Jun;9(2):1141.

10. Snadden D, Kunzli MA. Working hard but working differently: a qualitative study of the impact of generational change on rural health care. CMAJ Open. 2017 Sep;5(3):E710-16. https://doi.org/10.9778/ cmajo.20170075 
11. Bragard I, Fleet R, Etienne AM, et al. Quality of work life of rural emergency department nurses and physicians: A pilot study. BMC Res Notes. 2015 Apr;8(1):116. https://doi.org/10.1186/s13104-015-1075-2

12. Viscomi M, Larkins S, Gupta TS. Recruitment and retention of general practitioners in rural Canada and Australia: a review of the literature. Can J Rural Med. 2013 Winter;18(1):13-23.

13. Mayo E, Mathews M. Spousal perspectives on factors influencing recruitment and retention of rural family physicians. Can J Rural Med. 2006 Fall;11(4):271-6.

14. Vanasse A, Scott S, Courteau J, et al. Canadian family physicians' intentions to migrate: associated factors. Can Fam Physician. 2009 Apr;55(4):396-97.e6.

15. Ampofo-Addo O, Mou H, Olfert R, et al. Location decisions of family physicians in Saskatchewan: What really matters? Can J Rural Med. 2016 Winter;21(1):7-12.

16. Kelley M Lou, Kuluski K, Brownlee K, et al. Physician satisfaction and practice intentions in Northwestern Ontario. Can J Rural Med. 2008 Summer;13(3):129-35.

17. Jutzi L, Vogt K, Drever E, et al. Recruiting medical students to rural practice: Perspectives of medical students and rural recruiters. Can Fam Physician. 2009 Jan;55(1):72-73.el-4.

18. Chauban TS, Jong M, Buske L. Recruitment trumps retention: results of the 2008/09 CMA Rural Practice Survey. Can J Rural Med. 2010 Summer;15(3):101-7.

19. Lu DJ, Hakes J, Bai M, et al. Rural intentions: factors affecting the career choices of family medicine graduates. Can Fam Physician. 2008 Jul;54(7):1016-17.e5.

20. Parlier AB, Galvin SL, Thach S, et al. The Road to Rural Primary Care: A Narrative Review of Factors That Help Develop, Recruit, and Retain Rural Primary Care Physicians. Acad Med. 2018 Jan;93(1):130-40. https://doi.org/10.1097/ACM.0000000000001839

21. Soles TL, Ruth Wilson C, Oandasan IF. Family medicine education in rural communities as a health service intervention supporting recruitment and retention of physicians Advancing Rural Family Medicine: The Canadian Collaborative Taskforce. Can Fam Physician. 2017 Jan;63(1):32-8.

22. Strasser R, Neusy AJ. Context counts: training health workers in and for rural and remote areas. Bull World Health Organ. 2010 Oct;88(10):777-82. https://doi.org/10.2471/BLT.09.072462

23. Orzanco MG, Lovato C, Bates J, et al. Nature and nurture in the family physician's choice of practice location. Rural Remote Health. 2011;11(3):1849.

24. Beauchamp J, Bélanger M, Schofield A, et al. Recruiting doctors from and for underserved groups: Does New Brunswick's initiative to recruit doctors for its linguistic minority help rural communities? Can J Public Health. 2013 Jun;104(6 Suppl 1):S44-8.

25. Rourke J, Dewar D, Harris K, et al. Strategies to increase the enrolment of students of rural origin in medical school: Recommendations from the Society of Rural Physicians of Canada. CMAJ. 2005;172(1):62-5. https://doi.org/10.1503/cmaj.1040879

26. Lee J, Walus A, Billing R, et al. The role of distributed education in recruitment and retention of family physicians. Postgrad Med J. 2016 Aug;92(1090):436-40. https://doi.org/10.1136/ postgradmedj-2015-133577

27. Curran V, Rourke J. The role of medical education in the recruitment and retention of rural physicians. Med Teach. 2004 May;26(3):265-72. https://doi.org/10.1080/0142159042000192055

28. Bly J. What is medicine? Recruiting high-school students into family medicine. Can Fam Physician. 2006 Mar;52:329-34.
29. Rourke JTB. A rural and regional community multi-specialty residency training network developed by the University of Western Ontario. Teach Learn Med. 2005 Fall;17(4):376-81. https://doi.org/10.1207/ $\underline{\text { s15328015tlm1704_11 }}$

30. Mian O, Hogenbirk JC, Warry W, et al. How underserviced rural communities approach physician recruitment: changes following the opening of a socially accountable medical school in northern Ontario. Can J Rural Med. 2017;22(4):139-47.

31. Jamieson JL, Kernahan J, Calam B, et al. One program, multiple training sites: does site of family medicine training influence professional practice location? 2013 Oct-Dec;13(4):2496.

32. Myroniuk L, Adamiak P, Bajaj S, et al. Recruitment and retention of physicians in rural Alberta: the spousal perspective. 2016 Jan Mar;16(1):3620.

33. Pong RW. Strategies to overcome physician shortages in northern Ontario: a study of policy implementation over 35 years. Hum Resour Health. 2008 Nov;6(1):24. https://doi.org/10.1186/1478-4491-6-24

34. van Diepen K, MacRae M, Paterson M. Use of clinical placements as a means of recruiting health care professionals to underserviced areas in Southeastern Ontario: Part 2 - Community perspectives. Aust J Rural Health. 2007 Feb;15(1):29-34. https://doi.org/10.1111/j.14401584.2007.00846.x

35. MacRae M, van Diepen K, Paterson M. Use of clinical placements as a means of recruiting health care students to underserviced areas in Southeastern Ontario: Part 1 - Student perspectives. Aust J Rural Health. 2007 Feb;15(1):21-8. https://doi.org/10.1111/j.14401584.2007.00845.X

36. Curran V, Rourke L, Snow P. A framework for enhancing continuing medical education for rural physicians: A summary of the literature. Med Teach. 2010 Nov;32(11):e501-8. https://doi.org/10.3109/014215 9X.2010.519065

37. Rourke JTB, Incitti F, Rourke LL, et al. Keeping family physicians in rural practice. Solutions favoured by rural physicians and family medicine residents. Can Fam Physician. 2003 Sep;49:1142-9.

38. Cameron PJ, Este DC, Worthington CA. Physician retention in rural Alberta: key community factors. Can J Public Health. 2010 JanFeb;101(1):79-82.

39. Mathews M, Edwards AC, Rourke JTB. Retention of provisionally licensed international medical graduates: a historical cohort study of general and family physicians in Newfoundland and Labrador. Open Med. 2008;2(2):e62-9.

40. Islam $\mathrm{N}$. The dilemma of physician shortage and international recruitment in Canada. Int J Health Policy Manag. 2014 May;3(1):2932. https://doi.org/10.15171/ijhpm.2014.53

41. Woloschuk W, Lemay JF, Wright B. What is the financial state of medical students from rural backgrounds during tuition fee deregulation? Can J Rural Med. 2010 Fall;15(4):156-60.

42. MacQueen IT, Maggard-Gibbons M, Capra G, et al. Recruiting Rural Healthcare Providers Today: a Systematic Review of Training Program Success and Determinants of Geographic Choices. J Gen Intern Med. 2018 Feb;33(2):191-99. https://doi.org/10.1007/s11606-017-4210-Z

43. Sempowski IP. Effectiveness of financial incentives in exchange for rural and underserviced area return-of-service commitments: systematic review of the literature. Can J Rural Med. 2004 Spring;9(2):82-88. 